\title{
An uncoupling protein 2 gene variant is associated with a raised body mass index but not Type II diabetes
}

\author{
P. G. Cassell ${ }^{1}$, M. Neverova ${ }^{2}$, S. Janmohamed ${ }^{1}$, N. Uwakwe ${ }^{1}$, A. Qureshi ${ }^{1}$, M. I. McCarthy ${ }^{3}$, P.J. Saker ${ }^{3}$, L. Albon ${ }^{1}$, \\ P. Kopelman ${ }^{1}$, K. Noonan ${ }^{1}$, J. Easlick ${ }^{2}$, A. Ramachandran ${ }^{4}$, C. Snehalatha ${ }^{4}$, C. Pecqueur ${ }^{5}$, D. Ricquier ${ }^{5}$, C. Warden ${ }^{2}$, \\ G. A. Hitman ${ }^{1}$ \\ ${ }^{1}$ Medical Unit and Clinical Biochemistry, St. Bartholomew's and The Royal London School of Medicine and Dentistry, London, \\ United Kingdom \\ ${ }^{2}$ Rowe Program in Genetics, University of California, Davis, California, United States of America \\ ${ }^{3}$ Department of Metabolic Medicine, Imperial College School of Medicine at St. Mary's, London, United Kingdom \\ ${ }^{4}$ Diabetes Research Centre, Chennai, India \\ ${ }^{5}$ Centre de Recherche sur L'Endocrinologie Moléculaire et le Développement, Meudon, France
}

\section{Abstract}

Aims/hypothesis. Linkage between markers close to the uncoupling protein 2 and 3 genes (11q13) and resting metabolic rate and a pre-diabetic phenotype have been found. The syntenic region in mouse has been found to be linked to quantitative traits associated with obesity and diabetes. UCP2 and UCP3 could therefore have an important role in body weight regulation and susceptibility to diabetes. We investigated a recently identified variant of the $U C P 2$ gene in exon 8 as a marker for glucose and weight homeostasis.

Methods. Length variation of the UCP2 exon 8 variant was studied by the polymerase chain reaction and agarose gel electrophoresis. Sequence variants of the UCP3 gene were sought by semi-automated DNA sequencing.

Results. In 453 South Indian subjects, we found an association in women between the $U C P 2$ exon variant and body mass index $(p=0.018)$. These findings were replicated in a separate group of South Indian subjects $(n=143, p<0.001)$ irrespective of sex. Although no association was found between the $U C P 2$ exon 8 variant and overt obesity in British subjects, the $U C P 2$ genotype of obese women $(n=83)$ correlated with fasting serum leptin concentration $(p=0.006)$ in the presence of extreme obesity. These observations could not be explained by tight linkage disequilibrium with a coding region variant in the region of the $U C P 3$ gene of biological significance. Lastly, no association was found between $U C P 2$ and Type II (non-insulin-dependent) diabetes using either a family based design ( 85 families) or case control study (normal glucose tolerance $n=335$, impaired glucose tolerance $n=42$, Type II diabetes $n=76$ ).

Conclusion/interpretation. We have described a $U C P 2$ gene exon 8 variant that may affect susceptibility to weight gain by influencing regulation of leptin. [Diabetologia (1999) 42: 688-693]

Keywords Uncoupling protein genes, obesity, leptin, polymorphism.
The regulation of body fat equilibrium in mammals depends on a balance between diet and energy expenditure. Energy expenditure occurs as a result of a combination of resting metabolic rate, physical exercise and non-shivering thermogenesis. It has become increasingly evident that even small calorific inequal-

Received: 14 September 1998 and in final revised form: 25 January 1999

Corresponding author: Prof. G. A. Hitman, Medical Unit, The Royal London Hospital, Whitechapel, London E1 1BB, UK Abbreviations: UCP, Uncoupling protein; BAT, brown adipose tissue; WAT, white adipose tissue. ities can lead to an increase in fat storage and obesity. There is also an intimate association between increasing body weight and Type II (non-insulin-dependent) diabetes even in populations in which obesity is not a common problem. The recent addition of two new uncoupling proteins (UCP), UCP2 and UCP3 to the mitochondrial carrier protein family of genes provides new opportunities to study thermogenesis in humans [1-3]. Activated uncoupling proteins promote proton transport and consequently decrease the proton electrochemical potential gradient across the inner mitochondrial membrane. This uncouples oxidative phosphorylation of ADP to ATP, leading to generation of heat [4]. A close relation between obesity in mice 
and uncoupling protein 1 (UCP1) gene expression in brown adipose tissue (BAT) has been well established, although UCP1 knockout mice do not become obese [5]. The lack of substantial BAT in adult humans suggests that UCP1 has a limited role in thermogenesis in man. Associations between polymorphism of the UCP1 gene and various aspects of obesity have been reported, although these have not been consistent [6-7]. UCP2 and UCP3 (long transcript) both have six predicted transmembrane domains, as do UCP1 and other members of the mitochondrial carrier family of ion transporters of the inner mitochondrial membrane $[1,2,8]$. UCP2 has a wide tissue expression including white adipose tissue (WAT) whilst $U C P 3$ is mainly expressed in skeletal muscle $[2,3]$. Two recent studies have found linkage between markers in the vicinity of the uncoupling protein 2 and 3 genes (11q13), firstly with a resting metabolic rate in a French Canadian population [9], and secondly a suggestive linkage with a prediabetic phenotype, ( $2 \mathrm{~h}$ OGTT insulin concentrations) in Pima Indians [10]. Furthermore, the syntenic region in mouse has been found to be linked to quantitative traits associated with obesity and diabetes $[11,12]$. These findings suggest that UCP2 and UCP3 possibly have an important role in body weight regulation and the susceptibility to Type II diabetes in humans.

The primary purpose of our experiments was to study a recently identified UCP2 exon 8 variant [13] as a determinant of body mass index (BMI) and Type II diabetes in a group of South Indian subjects. This ethnic group was chosen for several reasons. Firstly, obesity is not as common in South Indians compared with European or North American Caucasians [14]. The effect of genetic variants might therefore be more pronounced in an ethnic group as yet not fully exposed to environmental factors that promote obesity compared with one in which the majority of the recent rise in the prevalence of obesity can be explained by modern lifestyle. Secondly, we had access to well characterised study groups including population and family based samples [14, 15]. On finding an association between the exon $8 \mathrm{UCP} 2$ variant and BMI, we then proceeded to study a British Caucasoid group for an association with overt obesity. We further hypothesised that the presence of extreme obesity would unmask a defect of leptin secretion in those with the UCP2 variant, much like insulin resistance unmasks a beta-cell defect in those genetically susceptible to Type II diabetes.

\section{Subjects and methods}

South Indian cross-sectional survey. We recruited 453 South Indian subjects from Chennai as part of an urban survey of the prevalence of diabetes and associated risk factors. This number represents the majority of those subjects in whom whole blood was available and represents four of the eight colonies screened [14]. The mean age of the subjects was $45 \pm 12$ years, mean BMI $22.5 \pm 4.2 \mathrm{~kg} / \mathrm{m}^{2}$ and $48.6 \%$ were female; $73.7 \%$ had normal glucose tolerance, $9.4 \%$ impaired glucose tolerance and $16.9 \%$ Type II diabetes.

South Indian families. Eighty-five South Indian families (255 members) were recruited as previously described [14]. For this experiment, families were studied consisting of the Type II diabetic proband and both parents. The mean age of onset of Type II diabetes in the probands was $33.8 \pm 9.9$ years, BMI $26.6 \pm 4.7 \mathrm{~kg} / \mathrm{m}^{2}$ and $36 \%$ were female. The treatment of the probands consisted of diet control (6\%), oral hypoglycaemics $(80 \%)$, and insulin $(14 \%)$. In the fathers, the mean age was $64.6 \pm 6.8$ years and mean BMI $25.2 \pm 9.6 \mathrm{~kg} / \mathrm{m}^{2}$ and the figures in the mothers for age were $57.7 \pm 6.5$ years and mean BMI $25.7 \pm 4.3 \mathrm{~kg} / \mathrm{m}^{2}$.

British Caucasoids. One hundred and fifty-six obese subjects defined by a BMI of greater than $30 \mathrm{~kg} / \mathrm{m}^{2}$ were recruited from the Obesity Clinic at The Royal London Hospital $(n=116)$ or by local advertisement $(n=40)$. The mean BMI was $40.3 \pm 6.4 \mathrm{~kg} / \mathrm{m}^{2}$ (range $30-67$ ), mean age was $44.0 \pm 11.5$ and $86 \%$ were female. We recruited 91 slim control subjects (males, BMI $<27$ and females, BMI $<25 \mathrm{~kg} / \mathrm{m}^{2}$ ) from amongst the staff at The Royal London Hospital. The mean BMI was $21.6 \pm 2.0 \mathrm{~kg} / \mathrm{m}^{2}$ (range 17.3-26.3), mean age $31.9 \pm 9.5$ years and $71 \%$ were female. A dietary review confirmed that none of the obese subjects was following a very restrictive diet at the time of venesection.

Method. Genomic DNA was extracted from blood samples collected in EDTA using the Qiamp 96 system (Qiagen, Crawley, UK). DNA was amplified using primers flanking the insertion in exon 8 (5'-forward CAGTGAGGGAAGTGGGAGG, 5 'reverse GGGGCAGGACGAAGATTC) of the UCP2 gene and separated by $2 \%$ agarose gel electrophoresis. Alleles were scored after ethidium bromide staining and recorded using an Alpha Imaging System (Alpha Innotech/Flowgen, Lichfield, UK). Homozygotes for the UCP2 exon 8 variant were verified by sequencing. The seven exons and part of the putative 5 ' regulatory region of the $U C P 3$ gene were sequenced in 15 subjects representing all UCP2 exon 8 variants and both ethnic groups. PCR amplification of UCP3 exons were done as previously described [16]. Primers for the regulatory region were based on sequences deposited with GDB (AF032871). Direct sequencing was by standard methods using an ABI 373 DNA Sequencer and TaqFS Dye terminator sequencing (Perkin-Elmer, Applied Biosystems, Warrington, UK).

Fasting serum leptins were taken in 83 obese women and determined by radioimmunoassay using a commercially available kit (Linco Research, St. Louis, Mo., USA). The kit uses a polyclonal antibody against highly purified human leptin and both the calibrators and ${ }^{125}$ I-labelled tracer are prepared with recombinant human leptin. The intra- and the inter-assay coefficients of variation were $3.4 \%$ and $3.6 \%$ respectively at a leptin concentration of $25.6 \mu \mathrm{g} / \mathrm{l}$.

Statistical analysis. Contingency tables were analysed by Chi square and continuous variables by ANOVA (SPSS for Windows, version 7.5). In the families, transmission of alleles from the parents to the Type II diabetic proband was analysed by the extended transmission disequilibrium test (ETDT) [17]. 
Table 1. South Indian subjects; UCP2 exon 8 genotypes by BMI

\begin{tabular}{|c|c|c|c|c|c|c|c|c|c|c|}
\hline & \multicolumn{3}{|l|}{ DD } & \multicolumn{3}{|l|}{ ID } & \multicolumn{3}{|l|}{ II } & \multirow[t]{2}{*}{$p$ value } \\
\hline & $n$ & BMI & $95 \% \mathrm{CI}$ & $n$ & BMI & $95 \% \mathrm{CI}$ & $n$ & BMI & $95 \% \mathrm{CI}$ & \\
\hline $\begin{array}{l}\text { South Indian parents } \\
\text { of Type II probands }\end{array}$ & 91 & 24.9 & $24.2-25.6$ & 47 & 24.1 & $23.0-25.2$ & 5 & 32.7 & $25.8-39.5$ & $<0.001$ \\
\hline $\begin{array}{l}\text { Urban cross-sectional } \\
\text { survey male }\end{array}$ & 155 & 22.1 & $21.4-22.6$ & 65 & 22.3 & $21.4-23.2$ & 13 & 20.6 & $18.3-22.9$ & 0.33 \\
\hline $\begin{array}{l}\text { Urban cross-sectional } \\
\text { survey female }\end{array}$ & 149 & 23.2 & $22.5-24.0$ & 62 & 22.1 & $21.0-23.2$ & 9 & 26.4 & $22.9-29.9$ & 0.018 \\
\hline
\end{tabular}

Table 2. Fasting serum leptin and UCP2 exon 8 genotypes in British Caucasoid female obese subjects

\begin{tabular}{llll}
\hline UCP2 genotype & $n$ & Mean leptin & $95 \%$ CI \\
\hline DD & 44 & 43.5 & $38.7-48.2$ \\
ID & 35 & 32.6 & $27.9-37.4$ \\
II & 4 & 45.6 & $18.7-72.5$ \\
\hline$p=0.006$ & & &
\end{tabular}

\section{Results}

We defined three $U C P 2$ genotypes (II, ID and DD) according to length variation of exon 8 , depending on the presence of an insertion or deletion. The exon $8 \mathrm{I}$ homozygote was present only in $5 \%$ of both South Indian and British Caucasoid cohorts; the DD genotype was the most frequent genotype. Therefore, the 'I' allele was assumed to be the variant and the ' $D$ ' allele to be the normal or 'wild' allele. The UCP2 exon 8 variant was confirmed in our sample group by nucleotide sequencing of an 'I' homozygote and was found to be a 45 base pair insertion in the 3 ' non-coding region, which is a duplication of the $5^{\prime}$ preceding 45 base pairs. In the ' $D$ ' homozygote the insertion was not present.

In 453 South Indian subjects recruited from a cross-sectional survey, we found an association between $U C P 2$ exon 8 genotype and BMI in women (Table $1 ; p=0.018)$ but not in men $(p=0.33)$. In the women, the exon 8 I homozygotic subjects had higher BMIs than either the heterozygotic or D homozygotic ones. When the data was re-analysed using a covariate of age, the main effect was between BMI and genotype $U C P 2(p=0.015$; overall model $p=0.036)$. To replicate the positive BMI findings, a further 143 South Indian subjects (consisting of parents of Type II diabetic probands) were studied and a similar association was found (Table $1 ; p<0.0001$ ); this was true even when fathers and mothers were analysed separately. In British Caucasoid subjects no association was found between $U C P 2$ exon 8 genotype and overt obesity $(p=0.07)$ or for BMI within the obese subjects $(p=0.28)$. In obese women in whom fasting leptins were available $(n=83)$, an association was seen between fasting serum leptin concentration and $U C P 2$ exon 8 genotype (Table $2 ; p=0.006$ ). The low- est leptin values were associated with the heterozygotic subjects. Although the mean fasting leptin concentration in the four homozygotic subjects for the variant was higher than in the heterozygotic ones, the $95 \%$ confidence limits spanned the confidence limits for both the heterozygotic and the homozygotic wild subjects. This association was also found if fasting serum leptin was corrected for BMI $(p=0.004)$.

In South Indians, we found no association between Type II diabetes and the $U C P 2$ exon 8 variant in 85 families using the extended transmission disequilibrium test $(p=0.45)$ or in the cross-sectional survey $(3 \times 3$ Chi square, $p=0.83$; normal glucose tolerance $n=335$, impaired glucose tolerance $n=42$ and Type II diabetes $n=76$ ).

Sequencing of the coding regions of $U C P 3$ in 15 subjects, five for each $U C P 2$ exon 8 genotype from both South Indian and British Caucasian groups, showed no new mutations. Two previously described neutral polymorphisms in exon 3 (codon 99T $\rightarrow \mathrm{C}$ ) and on exon $5($ codon $200 \mathrm{C} \rightarrow \mathrm{T})$ [15] were found in our sample group. At codon 99 of the UCP3 gene 14 of 15 subjects sequenced had the T allele; the one remaining subject had the variant $\mathrm{C}$ allele and was homozygotic for the $\mathrm{D}$ allele at exon 8 of the $U C P 2$ gene. At codon 200 of the UCP3 gene, the most common allele in the 15 subjects (South Indian and British Caucasoid) was the T allele present in all five I homozygotes, four of five heterozygotes and three of five D homozygotes for the exon $8 U C P 2$ gene polymorphic site. In the putative regulatory region (encompassing exon 1 and 400 base pairs upstream) we identified a novel variant consisting of a $\mathrm{C}$ to $\mathrm{T}$ transversion located six bases upstream of the TATAA box. The $\mathrm{T}$ allele was present in three of six of each $U C P 2$ exon $8 \mathrm{D}$ homozygotes and ID heterozygotes whereas all $U C P 2$ exon 8 homozygotes were $U C P 3$ $\mathrm{C}$ homozygotes. Hence both $\mathrm{T}$ and $\mathrm{C}$ alleles are associated with the $U C P 2$ exon $8 \mathrm{D}$ allele.

\section{Discussion}

Two groups have studied the $U C P 2$ exon 8 variant $[13,18]$. In Pima Indians, an association was found between the $U C P 2$ exon 8 variant and both resting 
metabolic rate and BMI (although in the latter this was restricted to subjects older than 45 years). In French Caucasians, no association was found between the $U C P 2$ variant and overt obesity (serum leptin was not reported) although in their data set no I homozygotes were found for the $U C P 2$ variant. Several other groups have screened the $U C P 2$ gene for variants but none have found the exon 8 insertion [19-22]. The only variant detected in these studies was an alanine for valine substitution at codon 55 (A55V, exon 4). This causes a conservative amino acid change of no functional significance when assessed as activity of the protein in a yeast expression vector (unpublished data). Within a juvenile obese group of Danish subjects, heterozygous carriers of the A55V variant had a lower BMI than the alanine homozygotic subjects $(p=0.04)$, although no overall association between obesity and the exon 4 variant was found. This and the data on the Pima Indians would therefore support our own observations and indicate that whilst $U C P 2$ gene associations may not determine extreme obesity, they possibly influence weight homeostasis. This would suggest that the genes determining the range of BMI are not necessarily the same as those determining overt obesity.

The data in obese British Caucasoid women indicate that the exon 8 variant allele is associated with a lower serum leptin concentration than would be expected by the BMI in the presence of extreme obesity. This suggests a changed interaction between BMI, leptin and UCP2 as a cause of obesity in a small proportion of patients. Leptin receptors have been found on a variety of tissues in addition to the central nervous system, including pancreatic islet cells, haemopoietic cells and adipocytes [23]. Indeed, in humans and rodents, it has been observed that leptin modulates $U C P 2$ expression in adipocytes and islets independently of dietary intake [24]. A recent study has shown a positive correlation between UCP2 mRNA levels in adipose tissue and BMI; furthermore, calorie restriction in six lean and five obese subjects increased both UCP2 and UCP3 mRNA expression [25]. The intriguing relation between UCP2 genotype and serum leptin concentration that we have found is strongly supported by the recent findings of Surwit et al. who have identified a quantitative trait locus for leptin in the same chromosomal region as $U C P 2$ and $U C P 3$ in a mouse model of diet induced obesity and diabetes (personal communication). We would therefore speculate that $U C P 2$ gene expression in white adipose tissue could regulate leptin concentrations. Genetically determined low leptin concentrations, however, are insufficient to lead to overt obesity by themselves but are possibly contributors to weight gain.

The exon 8 variant located in the 3 ' untranslated region of the gene might have an effect on UCP2 mRNA stability. This in turn could affect protein expression and determine body weight by influencing energy ex- penditure and thermogenesis. Any reduction in UCP2 mRNA stability could compromise a subject's ability to remove excess calories through thermogenesis, especially in a person with a propensity to obesity from other genetic or environmental influences. This hypothesis is supported by recent studies that found reduced $U C P 2$ mRNA levels in the visceral fat of obese but not lean subjects [26]. Furthermore, a separate group has also reported decreased $U C P 2$ (but not $U C P 3)$ mRNA expression in skeletal muscles of obese subjects [27]. Alternatively, the $U C P 2$ variant could be in linkage disequilibrium with another variant within $U C P 2$ or $U C P 3$ so far not detected. The $3{ }^{\prime}$ extremity of $U C P 3$ is located within less than $100 \mathrm{~kb}$ upstream of the transcriptional start site of $U C P 2$ [8]. Although $U C P 2$ expression is induced by diet, not all the tissues that express $U C P 2$ have a major role in thermogenesis and therefore its role in regulating energy expenditure is still not clear [1]. UCP3 in humans is mainly expressed in skeletal muscle [3] and this tissue is responsible for the bulk of thermogenesis. $U C P 3$ therefore makes an attractive candidate gene for both obesity and Type II diabetes. Our UCP3 sequencing data make it unlikely that the $U C P 2$ exon 8 variant is in tight linkage disequilibrium with any biologically significant mutations in the $U C P 3$ coding region which would lead to amino acid substitutions. The only variants found were the same as those recently reported in Danish subjects, consisting of two silent amino acid changes in exon 3 and 5 [16]. We cannot exclude, however, that variants of UCP3 not tightly linked to the $U C P 2$ exon 8 insertion variant will be found in some obese subjects as our study was not set up to address this question. Indeed, we did observe a novel $U C P 3$ regulatory region variant. Further studies are required to determine whether this variant is of functional significance and whether an association exists between it and either diabetes or obesity.

The negative result we have found in Type II diabetes in the South Indians is in accord with three other recently reported studies, using different methodologies and markers. One of these studies was unable to link chromosomal markers close to $U C P 2$ to Type II diabetes [28], whilst another found no association between Type II diabetes and the UCP2 A55V variant [19]. Within the Type II diabetic families, the former study did not find evidence of linkage between $U C P 2$ and either BMI or waist-to-hip ratio although the lod scores were inconclusive at 0.89 and 0.99 , respectively [28]. The A55V and an additional alanine to threonine at position 232 UCP2 variants have also been studied in Japanese subjects and no association with Type II diabetes were found [21]. Although a direct role of UCP2 in Type II diabetes seems unlikely, based on the genetic data, it is still conceivable that in some ethnic groups variants of UCP3 possibly contribute to the pathogenesis of Type II diabetes. Indeed, mRNA levels of UCP3 have been found to be 
considerably reduced in skeletal muscle of Type II diabetic patients compared with control subjects [29].

In conclusion, the UCP2 exon 8 variant is associated with increased BMI but not with Type II diabetes in a South Indian study group. Although no association was seen between UCP2 genotype and overt obesity in the British Caucasoid subjects, lower serum leptin concentrations were associated with the $U C P 2$ variant in the presence of extreme obesity. This is the first data suggesting that the $U C P 2$ gene or a closely linked locus might influence susceptibility to weight gain by affecting regulation of serum leptin.

Acknowledgements. Recruitment and characterisation of the British Caucasoid patients were greatly helped by the assistance of C. Grace, G. Hood and B. McLaughlin (St Bartholomew's and the Royal London School of Medicine and Dentistry). This work was supported by the Wellcome Trust (G. A. Hitman), Centre National de la Recherche Scientifique, Servier (D. Ricquier), Association de Recherche sur le Cancer (D. Ricquier), Human Frontier Science Programme Organisation (D. Ricquier), National Institute of Health DK52581, DK35747 and HL55 798 (C. Warden).

\section{References}

1. Fleury C, Neverova M, Collins S et al. (1997) Uncoupling protein-2: a novel gene linked to obesity and hyperinsulinaemia. Nat Genet 15: 269-272

2. Gimeno RE, Dembski M, Weng X et al. (1997) Cloning and characterization of an uncoupling protein homolog: a potential molecular mediator of human thermogenesis. Diabetes 46: 900-906

3. Boss O, Samec S, Paoloni-Giacobino et al. (1997) Uncoupling protein-3: a new member of the mitochondrial carrier family with tissue-specific expression. FEBS Lett 408: 39-42

4. Himms-Hagen J (1990) Brown adipose tissue thermogenesis: interdisciplinary studies FASEB J 4: 2890-2898

5. Enerback S, Jacobsson A, Simpson EM et al. (1997) Mice lacking mitochondrial uncoupling protein are cold-sensitive but not obese. Nature 387: 90-94

6. Clement K, Ruiz J, Cassard-Doulcier AM, Bouillaud F et al. (1996) Additive effect of $A \rightarrow G(-3826)$ variant of the uncoupling protein gene and the Trp64Arg mutation of the beta 3-adrenergic receptor gene on weight gain in morbid obesity. Int J Obes Relat Metab Disord 20: 1062-1066

7. Oppert JM, Vohl MC, Chagnon M et al. (1994) DNA polymorphism in the uncoupling protein (UCP) gene and human body fat. Int J Obes Relat Metab Disord 18: 526-531

8. Solanes G, Vidal-Puig A, Grujic D, Flier JS, Lowell BB (1997) The human uncoupling protein-3 gene. Genomic structure, chromosomal localization, and genetic basis for short and long form transcripts. J Biol Chem 272: 25433-25436

9. Bouchard C, Perusse L, Chagnon YC, Warden C, Ricquier D (1997) Linkage between markers in the vicinity of the uncoupling protein 2 gene and resting metabolic rate in humans. Hum Mol Genet 6: 1887-1889

10. Pratley RE, Thompson DB, Bogardus C (1998) An Autosomal Gene Scan for loci linked to prediabetic phenotypes in Pima Indians. J Clin Invest 101: 1757-1764

11. Yoshioka M, Kayo T, Ikeda T, Koizumi A (1997) A novel locus, Mody4, distal to D7Mit189 on chromosome 7 deter- mines early-onset NIDDM in non-obese C57BL/6 (Akita) mutant mice. Diabetes 46: 887-894

12. Surwit RS, Wang S, Petro AE, Sanchis D, Raimbault S, Ricquier D, Collins S (1998) Diet-induced changes in uncoupling proteins in obesity-prone and obesity-resistant strains of mice. Proc Natl Acad Sci USA 95: 4061-4065

13. Walder K, Norman RA, Hanson RL et al. (1998) Association between uncoupling protein polymorphisms (UCP2UCP3) and energy metabolism/obesity in Pima Indians. Hum Mol Genet 7: 1431-1435

14. Ramachandran A, Snehalatha C, Dharmaraj D, Viswanathan M (1992) Prevalence of glucose intolerance in Asian Indians. Urban-rural difference and significance of upper body adiposity. Diabetes Care 15: 1348-1355

15. McCarthy MI, Hitman GA, Shields DC et al. (1994) Family studies of non-insulin-dependent diabetes mellitus in South Indians. Diabetologia 37: 1221-1230

16. Urhammer SA, Dalgaard LT, Sorensen TI et al. (1998) Organisation of the coding exons and mutational screening of the uncoupling protein 3 gene in subjects with juvenileonset obesity. Diabetologia 41: 241-244

17. Sham PC, Curtis D (1995) An extended transmission/disequilibrium test (TDT) for multi-allele marker loci. Ann Hum Genet 59: 323-336

18. Otabe S, Clement K, Rich N et al. (1998) Mutation screening of the human UCP2 gene in normoglycaemic and NIDDM morbidly obese patients. Diabetes 47: 840-842

19. Urhammer SA, Dalgaard LT, Sorensen T et al. (1997) Mutational analysis of the coding region of the uncoupling protein 2 gene in obese NIDDM patients: impact of a common amino acid polymorphism on juvenile and maturity onset forms of obesity and insulin resistance. Diabetologia 40: 1227-1230

20. Argyropoulos G, Brown AM, Peterson R, Likes C, Watson D, Garvey WT (1998) Structure and organization of the human uncoupling protein 2 gene and identification of a common biallelic variant in Caucasian and Afro-American subjects. Diabetes 47: 685-687

21. Kubota T, Mori H, Tamori Y et al. (1998) Molecular screening of uncoupling protein 2 gene in patients with non-insulin-dependent diabetes mellitus or obesity. J Clin Endocrinol Metab 83: 2800-2804

22. Klannemark M, Orho M, Groop L (1998) No relationship between identified variants in the uncoupling protein 2 gene and energy expenditure. Eur J Endocrinol 9: 217-223

23. Auwerx J, Staels B (1998) Leptin. Lancet 351: 737-742

24. Zhou YT, Shimabukuro M, Koyama K et al. (1997) Induction by leptin of uncoupling protein-2 and enzymes of fatty acid oxidation. Proc Natl Acad Sci USA 94: 6386-6390

25. Millet L, Vidal H, Andreelli F et al. (1997) Increased uncoupling protein-2 and -3 mRNA expression during fasting in obese and lean humans. J Clin Invest 100: 2665-2670

26. Oberkofler H, Liu YM, Esterbauer H, Hell E, Krempler F, Patsch W (1998) Uncoupling protein-2 gene: reduced mRNA expression in intraperitoneal adipose tissue of obese humans. Diabetologia 41: 940-946

27. Nordfors L, Hoffstedt J, Nyberg B, Thörne A, Arner P, Schalling M, Lönnqvist F (1998) Reduced gene expression of UCP2 but not UCP3 in skeletal muscle of human obese subjects. Diabetologia 41: 935-939

28. Elbein SC, Leppert M, Hasstedt S (1997) Uncoupling protein 2 region on chromosome 11q13 is not linked to markers of obesity in familial type 2 diabetes. Diabetes 46: 2105-2107

29. Krook A, Digby J, O'Rahilly S, Zierath JR, Wallberg-Henriksson $H$ (1998) Uncoupling protein 3 is reduced in skeletal muscle of NIDDM patients. Diabetes 47: 1528-1531 